\section{TREATMENT OF MENINGOCELE, HYDROCELE,} ETC.

By Brigade-Surgeon-Lieutenant-Colonel T. H. HENDLEy, C.I.E.

THE successful treatment by operation of two large meningoceles by Mr. Spanton, which are reported in the BRITISH Medical JouRnal of October 9 th, indicates that the rate of mortality is not so high as has been usually stated. I can confirm this from my own practice. Last year I performed two such operations on Hindu infants at the Mayo Hospital, Jeypore (Rajputana, India). In each case the tumour was about the size of a turkey's egg, and had a neck which protruded through an aperture into which a finger could be introduced for a short distance into the cranial cavity in the course of the operation. The skin over the tumours was thick and covered with hair, but was thin and distended at the base. I operated in both cases in the same manner.

After shaving off the hair I made an incision and dissected off the skin until I reached the bluish-looking sac, which I opened and allowed the contents (in both cases quite fluid) to escape. I then passed a needle armed with a doubled piece of silkwiorm gut through the pedicle, and tied the divided portions firmly round the neck of the sac twice over so as to securely plug the opening in the skull, and with the same object as Mr. Spanton had, or as I have in view in a case of hernia, to close up the inguinal canal. I then cut off the portion of the tumour outside the sac, as well as the superfluous skin, and dressed the wound with iodoform and boric lint. In each case recovery was rapid, without increase of temperature or trouble of any kind.

The above were the only cases of meningocele I have operated upon, and I was induced to undertake them by my success in dealing with large inguinal herniæ and hydroceles. One case of hydrocele is worthy of notice. After dissecting out the sac from the scrotum, and evacuating its contents, I found that my finger could he passed up within the sac into the abdomen as far as the umbilicus. I was at first somewhat puzzled, but soon had no difficulty in drawing down the intrapelvic part of the sac so as to ligature the neck of it. I was then able to pass the ends of the catgut thread through the pillars and walls of the abdominal ring, thus firmly cutting off all entrance into the peritoneal cavity. I used silkworm gut to close the large incision in the scrotum, and made a drain of catgut threads. Recovery was rapid and complete.

I take this opportunity of referring to a case in which I removed an ovarian cyst (unilocular) as large as a football, in December last. My friend Surgeon-Colonel Warburton kindly assisted me. It was interesting from the fact that, with the exception of a few trifling adhesions, its only connection with surrounding structures was by a pedicle 6 inches long, which was only as thick as a pencil. This was attached to the right ovary. The woman was soon convalescent.

\section{MEMORANDA:}

MEDICAL, SURGICAL, OBSTETRICAL, THERAPEUTICAL, PATHOLOGICAI, ETC.

A CASE OF GLYCOSURIA IN THE INSANE. In recording the following case $I$ desire to draw attention, first to the low specific gravity, ranging usually from roro to 1020, and only once reaching 1035. Secondly, to the recurrence of the glycosuria coincident with the fall of the weather temperature, and the recovery with the break of the frost, which I have noticed each winter since 1893. The patient has not appreciably lost weight (about 7 lbs.) or st rength, and has suffered very slightly from thirst. $\mathrm{He}$ has had neuritis of the frontal nerve on the right side, accompanied by a crop of herpes, and had pain and some loss of power in the right arm; both these have, however, passed away.

H. B. is a stout gentleman (present weight, 13 st. I I lbs.) aged 56 years, who has been insane since the age of 36 years : and mentally is an ordinary case of chronic insanity, such as may be found in every asylum. On November 9th, 1893, he complained of feeling "seedy" and of thirst. He was Hot losing flesh, as the periodic weighing showed, but sugar was discovered in his urine. He was put on a modified diabetic diet.

From November 9 th to 15 th the specific gravity ranged from 1008 to 1018, only once reaching 1026. November 15 th. Total amount of liquid taking during the day 190 ounces. Total amount of urine passed 100 ounces, containing a total of 1,000 grains of sugar.

After this the sugar gradually declined in amount until November 29th, when the note says : Patient drank $4 \frac{1}{2}$ pints, and passed 5 pints of urine containing no sugar; specific gravity, roro. He continued well until December, 1894, when sugar was found in the urine after having been absent all the summer. The urine was frequently tested. The diet was again modified without effect on the sugar, and the glycosuria continued until February 28th, 1895, the specific gravity ranging from 101 5 to 1018, the quantity of urine about normal, and sugar from 6 to 11 grains per ounce. The patient suffered no inconvenience except from the dietetic treatment. On March 5 th the sugar fell from an average of 5 grains per ounce to nothing, the weather, which had been cold, having become much warmer, and it was noticed during this attack that less sugar was passed on warmer than on cold days.

Sugar was again found in the urine on January 2nd, 1896 , lasting again through the cold weather to April 1st, 1896. Reappeared on December 25 th, at the same time as the commencement of the frost. Specific gravity 1034 (the highest recorded), sugar 3 grains per ounce. Codeia was ordered, as he was too much excited by the attempt to modify the diet, and it had failed to give relief on previous occasions.

The glycosuria continued until the return of warmer weather in March, 1897. He had an attack of influenza in May, followed by a rather sharp attack of bronchitis, on recovering from which he had a slight return of glycosuria, which, however, rapidly passed off without special treatment, leaving him in his usual health after about two weeks.

E. H. O. SaNKeY, M.A., M.B., B.C.Cantab., Resident Licensee of Boreatton Park Licensed House, Baschurch, Salop.

CASE OF ACUTE NECROSIS OF ALVEOLAR PROCESS OF SUPERIOR MAXILLA IN A BABY TWO DAYS AFTER BIRTH.

ON September 25th I attended Mrs. B., aged 28, in her first. confinement, which was quite normal though somewhat. tedious. Two days after birth the nurse called my attention to the baby, who had not yet opened its eyes. There was. slight chemosis of both eyelids, which I thought might have. been due to injury during birth. The nexi day I was re-. quested to examine its mouth, and on doing so I found the alveolar process of the left superior maxilla much swollen. The day following there was extensive sloughing, and after having removed the slough with a pair of forceps, I extracted two pieces of bone. The child progressed favourably under treatment until the twelfth day, when an erysipelatous eruption appeared on the abdomen, subsequently spreading to the genitals and nates. The baby died on the fifteenth doy, apparently from sapræmia. That I have never heard of necrosis coming on so soon after birth must be my excuse for reporting this case. I could get no history of syphilis, struma, etc, Ripley, Derby.

Frederic C. Wood, L.S.A.Lond. (Triple Qual.),

\section{A CASE OF TYPHOID FEVER TREATED BY THE} INJECTION OF PURE FERMENTS.

L. R., aged 13 years, residing at Camberley, was first seen on June 5 th. She had then been ill a few days with pains in her limbs and back, headache, sickness, and diarrhcea.

Physical Signs. - General feebleness, accompanied with a. bright malar flush, face rather anxious, skin hot, pulse quick and compressible, some dulness of comprehension as to ques:tions; abdomen full, with tenderness and gurgling on pressure over the right iliac region. The morning temperature was then $100^{\circ} \mathrm{F}$. The stools were of the typical pea-soupy, typhoid character. Typhoid fever was diagnosed.

Progress.- Succeeding symptoms tended to confirm this opinion; the stools became tinged and streaked with blocd, 